doi:10.1016/j.aquatox.2006.07.005

Copyright (c) 2006 Elsevier B.V. All rights reserved.

\title{
In vivo and in vitro Ah-receptor activation by commercial and fractionated pentabromodiphenylether using zebrafish (Danio rerio) and the DR-CALUX assay
}

\author{
R.V. Kuiper ${ }^{a} *$, A.J. Murk ${ }^{b}$, P.E.G. Leonards ${ }^{c}$, , G.C.M. Grinwis ${ }^{a}$, M. van den \\ Berg and J.G. $\operatorname{Vos}^{\mathrm{a}}$,
}

* Corresponding author. Tel.: +3130253 4298; fax: +31302534774.

\author{
aDepartment of Pathobiology, Faculty of Veterinary Medicine, Utrecht University, \\ Yalelaan 1, P.O. Box 80158, 3508 TD Utrecht NL, The Netherlands \\ ${ }^{\mathrm{b}}$ Section Toxicology, Wageningen University, Tuinlaan 5, P.O. Box 8000, 6700 EA \\ Wageningen, The Netherlands \\ ${ }^{\mathrm{C}}$ Netherlands Institute of Fisheries Research (RIVO), Haringkade 1, P.O. Box 68, \\ 1970 AB IJmuiden, The Netherlands \\ ${ }^{\mathrm{d}}$ Institute for Environmental Studies (IVM), Vrije Universiteit Amsterdam, De \\ Boelelaan 1087, 1081 HV Amsterdam, The Netherlands \\ ' Institute for Risk Assessment Sciences (IRAS), Utrecht University, Yalelaan 2, \\ P.O. Box 80176, 3508 TD Utrecht NL, The Netherlands \\ fLaboratory for Toxicology, Pathology and Genetics, National Institute of Public \\ Health and the Environment (RIVM), Antonie van Leeuwenhoeklaan 9, P.O. Box 1, \\ 3720 BA Bilthoven, The Netherlands
}

Received 10 April 2006; revised 3 July 2006; accepted 6 July 2006. Available online 14 July 2006.

\begin{abstract}
The present study addresses the toxicity of a commercial pentabrominated diphenylether (PeBDE) flame retardant mixture, DE-71, in a model aquatic vertebrate. Four weeks' exposure of juvenile zebrafish (Danio rerio) to waterborne DE-71 resulted in dose-dependent induction of CYP1A immunoreactivity, predominantly in the endocardium and the endothelium of larger blood vessels, such as ventral aorta and branchial arteries, as well as the larger hepatic and pancreatic blood vessels.
\end{abstract}

To investigate the impact of possible contaminating PBDD/Fs in the DE-71 product, the study was repeated after $D E-71$ had been fractionated into a nonplanar (cleaned PBDEs) and a planar fraction (PBDD/Fs). Zebrafish were exposed under similar conditions to the planar and cleaned DE-71 fractions, and to uncleaned DE-71. In addition, the above fractions were chemically analyzed and tested in a reporter gene assay (DR-CALUX) for their aromatic hydrocarbonreceptor (AhR) stimulating potencies. A relatively strong CALUX response was detected from the planar DE-71 fraction (19.7 ng TCDD equivalent (TEQ)/g DE$71)$, coinciding with a strong induction of CYP1A immunoreactivity in zebrafish. CYP1A immunoreactivity in zebrafish exposed to uncleaned DE-71 was intense, although the CALUX response was 10-fold less compared to the planar fraction. Only weak CYP1A immunoreactivity was found in fish exposed to cleaned DE-71, and none in control animals; no CALUX response was detected in cleaned DE-71. 
The present findings indicate that chemical impurities of the commercial PeBDE product account for AhR-mediated effects. Analytical isolation of a planar fraction from the commercial product increased the in vitro (DR-CALUX) signal 10 times. Immunohistochemistry showed a strong tissue specific reaction to DE-71 in vivo at these relatively low TEQ levels regardless of chemical pretreatment of the mix, reflecting the sensitivity of CYP1A induction in juvenile zebrafish to AhR agonists.

Keywords: Brominated flame retardants; CYP1A; Histology; Immunohistochemistry; PBDE; TEQ; Zebrafish

\section{Introduction}

Polybrominated diphenylethers (PBDEs) are abundantly used as flame retardants in synthetic products such as electronic equipment, building materials, and textiles. Release of these additives into the environment has resulted in widespread aquatic contamination, as evidenced by their presence in remote areas (de Boer et al., 1998, Ikonomou et al., 2002 and Vives et al., 2004). Particularly lower brominated PBDE congeners tend to bioaccumulate (de Wit, 2002 and Burreau et al., 2004), and increasing levels were detected in aquatic biota in a number of temporal trend studies. Whereas environmental concentrations of major pollutants such as dieldrin and hexachlorobenzene (HCB) decreased, increasing levels of PBDEs were detected in livers from cod caught in the North Sea over the years 1977-1987 (de Boer, 1989). Similarly, PBDE concentrations in fish from the Great Lakes increased over the years 1980-2000 (Zhu and Hites, 2004). Increasing PBDE levels were also reported higher up the food chain (e.g. in guillemot eggs from Sweden (1969-2000, Sellström et al., 2003), and in ringed seals from the Canadian Arctic (1981-2000, Ikonomou et al., 2002)). In fish, total PBDE levels as high as $4.6 \mu \mathrm{g} / \mathrm{g}$ lipid weight have been reported (Sellström et al., 1998). Despite the larger production volumes of higher brominated diphenylethers, tetra- and penta-brominated congeners predominate in biota, 2,2',4,4'-pentabromodiphenylther (BDE 47) being the most important (Anderson and Blomkvist, 1981, Watanabe et al., 1987, Sellström et al., 1993, Jansson et al., 1993 and de Boer, 1989). Since BDE 47 was not a breakdown product of higher brominated PBDEs by photolytic debromination (Söderström et al., 2004) or metabolism (Kierkegaard et al., 1999), commercial pentabrominated mixtures such as DE-71, which contain substantial amounts of BDE 47 , are the most likely source. Although in Europe, reduced use of lower brominated PBDEs caused levelling off (Kierkegaard et al., 2004) or even reduction (Sellström et al., 2003) of PBDE levels in biota, high production volumes in other areas and global redistribution (Birnbaum and Staskal, 2004 and Vives et al., 2004) present a continuous source for environmental exposure.

PBDEs may have adverse effects on biota in a number of ways. Several, particularly lower brominated, PBDE congeners, and especially their hydroxylated metabolites may modulate both estrogen receptor (Meerts et al., 2001 and Nakari and Pessala, 2005) and thyroid hormone receptor mediated effects (Schriks et al., 2006) in vitro. The detection of planar PHAHs (polybrominated dibenzo- $p$ dioxins, PBDDs, and dibenzofurans, PBDFs; Sanders et al., 2005 and Sakai et al., 2001 ) in commercial diphenylether mixtures is of additional concern, since PBDD/Fs show comparable toxicity as their identically substituted chlorinated homologues (Hornung et al., 1996, Behnisch et al., 2003 and Birnbaum et al., 2003). A number of reports on effects of PBDEs in fish are available. Prolonged oral exposure of sticklebacks (Gasterosteus aculeatus) to the commercial penta- 
BDE mixture, Bromkal 70-5DE, reduced spawning success and caused mild hepatic lipidosis and increased EROD activity (Holm et al., 1993); a mild induction of EROD activity was also reported in rainbow trout (Oncorhynchus mykiss) fry injected with Bromkal 70-5DE (Norrgren et al., 1993); these authors suggested that impurities in the commercial blends might be responsible. Conversely, EROD activity was decreased in rainbow trout orally exposed to tetra- and penta-BDE during 22 days; glutathion reductase activity was also decreased, whereas blood glucose and hematocrit showed a mild but statistically significant increase (Tjärnlund et al., 1998). Exposure of killifish (Fundulus heteroclitus) embryos to DE-71 via the water up to $100 \mu \mathrm{g} / \mathrm{l}$ did not result in induction of EROD activity, but delayed hatching up to 4.5 days and decreased swimming in response to external stimuli in larvae (Timme-Laragy et al., 2006). The possible role of endocrine disruption on sex steroid and thyroid hormonal homeostasis in vivo remains to be identified and the impact of possible planar contaminants in commercial mixtures has not been properly evaluated in aquatic species.

The present study focuses on histopathological changes to determine target organs for subacute toxicity of commercial pentabromo diphenylether (DE-71) in a popular aquatic vertebrate model species, zebrafish (Danio rerio), between 4 and 8 weeks of age when gonad sexual dimorphism develops (Hsiao and Tsai, 2003). Whole body serial sections cut at $40 \mu \mathrm{m}$ intervals were examined by lightmicroscopy with emphasis on thyroid, gonad and liver histology. Attention was also given to brain and pituitary gland, skin, gills, intestine, kidney, spleen and thymus. Immunohistochemistry using a monoclonal antibody directed against scup (Stenotomus chrysops) cytochrome P4501A (CYP1A) was performed to evaluate tissue patterns of CYP1A protein formation. The toxic potential of possible planar impurities (PBDD/Fs) was investigated in a separate in vivo experiment of similar design. The DE-71 sample was fractionated to separate PBDD/Fs from the (non-planar) PBDEs, based on the method developed for the separation of PCBs from PCDD/Fs by adsorption chromatography using $\mathrm{Al}_{2} \mathrm{O}_{3}$ (Ramos et al., 1997), and both fractions were chemically analyzed. Zebrafish were exposed to the non-planar fraction (further termed as cleaned DE-71), the planar fraction (PBDDs and PDDFs), and to uncleaned (untreated) DE-71, and PBDE levels were analyzed in whole fish to evaluate exposure. In addition, to assess dioxin-like potencies for each of the fractions in vitro, TCDD equivalents (TEQs) were determined in an AhR- activated reporter gene assay (DR-CALUX, Murk et al., 1996 and Murk et al., 1998).

\section{Materials and methods}

\subsection{Animals and their maintenance}

Zebrafish (D. rerio) were bred at the Institute of Risk Assessment Sciences (IRAS), Utrecht. Breeding stock is maintained on live Artemia salina and dry flake fish food (King British, Bradford, England), supplemented with Daphnia magna. From 2 days after hatching, larvae are fed from a culture containing protozoa grown on hay and banana peel. From the second week they accept the same diet as the adults. At 3 weeks of age, the animals were transferred to the exposure vessels, where they were fed dry flake food only. Testing was started after 1 week of acclimatization.

\subsubsection{Preparation of DE-71 stock solutions}

The non-planar (PBDEs) and planar (PBDD/Fs) fractions of DE-71 were prepared using basic $\mathrm{Al}_{2} \mathrm{O}_{3}$ (Merck, Darmstadt, Germany, mesh size 63-200 $\mu \mathrm{m}$ ) activated at $150^{\circ} \mathrm{C}$ for $12 \mathrm{~h}$. A stock solution of DE-71 (100 mg) in $50 \mathrm{ml}$ 
hexane/dichloromethane (DCM) (48:2, v/v, Promochem, Wesel, Germany) was prepared. Five milliliter of this solution was added to a glass column filled with $25 \mathrm{~g}$ of activated $\mathrm{Al}_{2} \mathrm{O}_{3}$. PBDEs were eluted from the column using $150 \mathrm{ml}$ hexane/DCM $(48: 2, \mathrm{v} / \mathrm{v})$, followed by $200 \mathrm{ml}$ of hexane/DCM $(9: 1, \mathrm{v} / \mathrm{v})$ (nonplanar DE-71 fraction). PBDD/Fs were subsequently eluted with $200 \mathrm{ml}$ of hexane/DCM $(1: 1, \mathrm{v} / \mathrm{v})$ (planar fraction). This procedure was repeated ten times. All non-planar fractions and all planar fractions were combined, and evaporated to $2 \mathrm{ml}$. An aliquot of the non-planar $(1 \mathrm{ml})$ and an aliquot of the planar fraction $(1 \mathrm{ml})$ was evaporated to dryness and again dissolved in $5 \mathrm{ml}$ DMSO (HPLC grade, Baker, Germany) to prepare dosing solutions. For preparation of uncleaned DE-71, $50 \mathrm{mg}$ DE-71 was dissolved in $50 \mathrm{ml}$ hexane/DCM, evaporated to dryness, and again dissolved in $5 \mathrm{ml}$ of DMSO.

\subsubsection{Chemical analysis of DE-71}

Uncleaned DE-71 was analyzed using a gas chromatograph (GC, 6890, Agilent Technologies, Germany) coupled to a 5973 mass spectrometer (MS, Agilent Technologies) in the electron capture negative ionization mode (ECNI) mode (MSD transferline $290^{\circ} \mathrm{C}$, source temperature $200^{\circ} \mathrm{C}$, quadrupole temperature $106{ }^{\circ} \mathrm{C}$, electron energy $70 \mathrm{eV}$ with methane $(3.25 \mathrm{ml} / \mathrm{min})$ as a reagent gas). Quantification and identification of PBDEs was carried out with the $\mathrm{Br}$ isotope cluster ( $\mathrm{m} / \mathrm{z} 79$ and 81$)$. Helium gas was used as carrier gas at a constant flow of $1.2 \mathrm{ml} / \mathrm{min}$. A $50 \mathrm{~m} \times 0.25 \mathrm{~mm} \times 0.25 \mu \mathrm{m} \mathrm{CP}-$ Sil 8 fused silica column was used. GC conditions were: oven temperature $90^{\circ} \mathrm{C}$ during $3 \mathrm{~min}$, then increased with $30{ }^{\circ} \mathrm{C} / \mathrm{min}$ and kept at $210^{\circ} \mathrm{C}$ for $20 \mathrm{~min}$; and finally increased to $290{ }^{\circ} \mathrm{C}$ with $5^{\circ} \mathrm{C} / \mathrm{min}$. Injection was pulsed splitless $\left(280^{\circ} \mathrm{C}\right)$ and the carrier gas was helium $(1.2 \mathrm{ml} / \mathrm{min})$.

PBDD/Fs were determined in the planar fraction using GCxGC using a TRACE 2D GC (ThermoElectron, Milan, Italy) coupled to a time-off-flight mass spectrometer (ThermoElectron, Austin, TX, USA). The MS was operated in the electron impact (EI) and in the ECNI mode using methane gas as reagent gas with a flow rate of $3 \mathrm{ml} / \mathrm{min}$. The data acquisition rate was $40 \mathrm{~Hz}$, electron energy $65 \mathrm{eV}$, and a mass range of $\mathrm{m} / \mathrm{z} 70-850$ was used. The MS transfer line was set at $300^{\circ} \mathrm{C}$ and the ion source at $190^{\circ} \mathrm{C}$. A $30 \mathrm{~m} \times 0.25 \mathrm{~mm} \times 0.25 \mu \mathrm{m} \mathrm{DB}-1$ (J\&W Scientific, Agilent) was used in the first dimension, and a $1 \mathrm{~m} \times 0.1 \mathrm{~mm} \times 0.1 \mu \mathrm{m} \mathrm{007-}$ $65 \mathrm{HT}$ column (Quadrex, New Haven, CT, USA) in the second dimension. Modulation was performed at the beginning of the second dimension column with a modulation period of $8 \mathrm{~s}$. One $\mu \mathrm{l}$ of the DE-71 fractions was splitless injected (injection temperature $280^{\circ} \mathrm{C}$ ) into a PTV injector with the split opening after $2 \mathrm{~min}$, using an autosampler. Helium was used as carrier gas at a flow rate of $1 \mathrm{ml} / \mathrm{min}$. GC conditions were: oven temperature $90^{\circ} \mathrm{C}$ during $3 \mathrm{~min}$, then increased with $30^{\circ} \mathrm{C} / \mathrm{min}$ and kept at $210^{\circ} \mathrm{C}$ for $20 \mathrm{~min}$; and finally increased to $290{ }^{\circ} \mathrm{C}$ with $5^{\circ} \mathrm{C} / \mathrm{min}$. For more details on the GCxGC-ECNI-TOF-MS systems see Korytar et al. (2005). The following PBDD/Fs were present in the analytical standard which was used for identification and quantification: 2,3,7,8-TeBDD, 1,2,3,7,8-PeBDD, 1,2,3,4,7,8-HxBDD, 1,2,3,6,7,8-HxBDD, 1,2,3,7,8,9-HxBDD, OBDD, 2,3,7,8-TeBDF, 1,2,3,7,8-PeBDF, 2,3,4,7,8-PeBDF, 1,2,3,4,7,8-HxBDF, $1,2,3,4,6,7,8-\mathrm{HpBDF}$ (all from Cambridge Isotope Laboratories, Inc.). Detection limits for tetra-, penta-, hexa-, and heptabrominated PBDD/Fs were 0.4, 0.02, 0.03 , and $0.03 \mathrm{mg} / \mathrm{kg} \mathrm{DE}-71$, respectively.

\subsubsection{Chemical analysis of zebrafish}

Fish samples from experiment B (see below) were rinsed with demineralized water to remove any remaining exposure water. The pooled homogenate of four 
animals per group was weighed, dried with sodium sulfate (Merck), and stored for $2 \mathrm{~h}$. An internal standard (CB112, Promochem) was added to the sample followed by an extraction with $10 \mathrm{ml}$ hexane/acetone $(3: 1, \mathrm{v} / \mathrm{v})$ using a vortex mixer. Extraction was repeated after $1 \mathrm{~h}$ and on the next day. The extracts were combined and evaporated to $1 \mathrm{ml}$. An aliquot of the extract was dried under nitrogen flow for gravimetrical determination of the lipid content. The residual extract was fractionated by silica gel (deactivated with $1.8 \% \mathrm{H}_{2} \mathrm{O}$, Merck) using $11 \mathrm{ml}$ isooctane (Promochem) and $25 \mathrm{ml}$ isooctane: diethylether (85:15, v/v; Promochem) as eluents. Finally, the silica eluate was evaporated to $1 \mathrm{ml}$ and the final analysis was carried out by GC-MS in the ECNI mode using the same conditions as for the DE-71 analysis.

\subsection{Experimental design}

\subsubsection{In vivo studies}

Groups of 20 zebrafish each with a starting age of 3 weeks were kept in 3 I glass beakers containing 2.5 I copper-free tap water. They were placed in a conditioned room (ambient temperature $25^{\circ} \mathrm{C}$, daily 12-h dark/light regimen). Water was refreshed by semistatic renewal, i.e. 2 I of water were replaced by fresh, preheated copper-free tap water three times weekly on Mondays, Wednesdays, and Fridays. Water temperature and oxygen content were checked immediately before each renewal. Acidity was monitored at regular intervals. The 4-week test period (age: 4-8 weeks) was started after 1 week of acclimatization.

In the first study (experiment A), 6 groups of 20 zebrafish were exposed via the water to a commercial mixture of penta-BDE (DE-71, batch 25008, provided by Great Lakes Chemical Corp., Herentals, Belgium), at nominal water concentrations of $0.0,0.010,0.032,0.10,0.32$, and $1.0 \mathrm{mg} \mathrm{DE}-71 / \mathrm{l}$ (Table $1 \mathrm{a}$ ). Animals were randomly assigned to the different exposure groups and tanks were positioned in random order. Prior to initial addition to the water, dosing solutions were prepared by dissolving DE-71 in dimethylsulfoxide (DMSO, Baker, Germany), using glass vials. Vials were left in the dark at room temperature on a platform shaker for $24 \mathrm{~h}$. During the experiment, they were stored in the dark at room temperature. DMSO concentration in the exposure medium was $0.01 \%$ in all groups, including the control. Exposure was initiated by adding $250 \mu \mathrm{l}$ of the dosing solution immediately after renewal. On subsequent renewals, $200 \mu \mathrm{l}$ of dosing solution was added.

Table 1a.

Nominal concentrations of DE-71 in water (0.01\% DMSO), mortality during, and size at the end of, experiment $A$

\begin{tabular}{|l|l|l|l|}
\hline Dose (mg/I) & Mortality & Length \pm S.D. $(\mathbf{m m})$ & Weight \pm S.D. (mg) \\
\hline 0.0 & $0 / 20$ & $15.4 \pm 1.4$ & $31.5 \pm 9.1$ \\
\hline 0.010 & $0 / 20$ & $16.3 \pm 1.2$ & $34.9 \pm 8.9$ \\
\hline 0.032 & $0 / 20$ & $15.3 \pm 1.6$ & $30.8 \pm 9.9$ \\
\hline 0.10 & $0 / 20$ & $14.7 \pm 1.7$ & $28.8 \pm 11.4$ \\
\hline 0.32 & $1 / 20$ & $14.9 \pm 2.2$ & $32.7 \pm 16.4$ \\
\hline 1.0 & $3 / 20$ & $12.9 \pm 1.5^{*}$ & $19.8 \pm 7.3^{*}$ \\
\hline
\end{tabular}

${ }^{*} p<0.05$. 
The second study (experiment B) was carried out under identical conditions. Seven groups of 20 animals were exposed to either water-borne DE-71 in nominal concentrations 0.10 and $1.0 \mathrm{mg} / \mathrm{l}$, the cleaned fraction of 0.10 and $1.0 \mathrm{mg} \mathrm{DE}-71 / \mathrm{l}$, the planar fraction of 0.10 and $1.0 \mathrm{mg} \mathrm{DE}-71 / \mathrm{l}$, or DMSO only (DMSO at $0.01 \%$ in all groups, Table $1 \mathrm{~b}$ ).

Table $1 b$.

Nominal concentrations of DE-71 and equivalents of nominal concentrations of DE-71 fractions in water (0.01\% DMSO), mortality during, and size at the end of, experiment B

\begin{tabular}{|l|l|l|l|l|}
\hline Exposure (mg DE-71/I) & Mortality & Length \pm S.D. (mm) & Weight \pm S.D. (mg) \\
\hline Control & & $0 / 20$ & $20.6 \pm 1.7$ & $66.1 \pm 17.7$ \\
\hline \multicolumn{5}{|l|}{} \\
\hline Uncleaned DE-71 & 0.1 & $0 / 20$ & $21.2 \pm 1.2$ & $71.7 \pm 11.6$ \\
\hline & 1 & $0 / 20$ & $19.6 \pm 2.1$ & $58.9 \pm 17.4$ \\
\hline \multicolumn{7}{|l|}{} & 0.1 & $0 / 20$ & $20.3 \pm 2.5$ & $63.8 \pm 22.2$ \\
\hline Cleaned DE-71 & 1 & $0 / 20$ & $19.4 \pm 2.0$ & $55.6 \pm 19.1$ \\
\hline & & & & $62.1 \pm 17.0$ \\
\hline & 0.1 & $0 / 20$ & $19.9 \pm 2.0$ & $59.6 \pm 18.3$ \\
\hline Planar fraction & 1 & $0 / 20$ & $19.8 \pm 2.2$ & \\
\hline
\end{tabular}

\subsubsection{Sampling and histological technique}

During the last day of the experiments, animals were not fed to minimize intestinal content. In this way, better fixation and less histological "dominance" of the intestines were achieved. At the end of the experimental periods, animals were killed in random order using a solution of $0.3 \mathrm{~g} \mathrm{TMS} / \mathrm{l}$ and $0.6 \mathrm{~g} \mathrm{NaHCO}_{3} / \mathrm{l}$ in preheated copper free tap water (TMS is 3-amino benzoic acid ethyl ester, methane sulfonate salt, Sigma-Aldrich, Steinheim, Germany). From all experimental groups, 16 animals were processed for histological examination. In experiment $\mathrm{B}$, remaining animals were frozen at $-20^{\circ} \mathrm{C}$ for chemical analysis. For histology, entire animals were fixed in Bouin's fixative, immediately after euthanasia. Animals that died during the experiments were excluded from histological examination because rapid autolysis renders these animals unsuitable for histopathology. After $12 \mathrm{~h}$, fixed animals were transferred to $70 \%$ ethanol. Length and weight of the animals surviving the entire experimental period were then determined and the animals were routinely processed and embedded in paraffin (two fish per paraffin block). Serial sections of approximately $4 \mu \mathrm{m}$ thick were cut at $40 \mu \mathrm{m}$ intervals to reveal small organs like thyroid follicles and pituitary gland. Hematoxylin-eosin (H\&E) staining was used for routine microscopy. Sections were randomized and coded before histological examination. Histological alterations were marked as absent, present, or severe, by two independent histopathologists.

For immunohistochemistry, sections were mounted on slides coated with $0.01 \%$ poly-L-lysine (PLL; Brunswick Chemie, Amsterdam, The Netherlands), and 
deparaffinized. A mouse monoclonal anti-scup CYP1A antibody (kindly provided by J.J. Stegeman, Woods Hole Oceanographic Institution, Woods Hole, MA, USA) was used as primary antibody. Immunoperoxidase staining was then performed according to Grinwis et al. (2000). A monoclonal mouse anti-proliferating cell nuclear antigen (PCNA) antibody (Dako, Glastrup, Denmark) with indirect immunoperoxidase staining (Grinwis et al., 2000) was used to examine possible effects on cell proliferation. To test for false positive results, negative controls were included in which the primary antibody was omitted or a primary monoclonal mouse anti-Chlamydia antibody (Clone C5, Argene Biosoft, Varilhes, France) was used in the procedure mentioned above. Proliferating testis was used as positive internal control for PCNA staining. For the semi-quantitative assessment of CYP1A induction, a total of three unstained, PLL-mounted slides containing liver, heart and gills were selected from randomly chosen specimens of each dose-group in experiment $A$. Immunohistochemistry was performed on all 18 slides simultaneously to prevent technique induced staining differences. Staining intensities in various organs were qualitatively assigned as not detectable, low, intermediate or high by two independent histopathologists. As each slide contained two specimens, six animals were viewed for each exposure group. For statistical analysis these pairs were counted as single observations. During microscopic evaluation of all slides, observers were not aware of the exposure concentration from which the slides originated. A similar procedure was applied to eight randomly selected PLL slides per group in experiment B.

\subsubsection{In vitro study}

Chemical-activated luciferase gene expression mediated by Ah-receptor activation (DR-CALUX) was used as described by Murk et al. (1998) to assess the AhR activating potential of DE-71, cleaned DE-71, and its planar fraction. In brief, H4IIE-cells transfected with the luciferase reporter gene plasmid: pGudLuc1.1 (H4IIE.luc cells), were exposed in triplicate to each of the mixtures in concentrations $0.008,0.08,1.6$ and $2.4 \mathrm{mg} \mathrm{DE}-71 / \mathrm{ml}$. A standard concentration series of TCDD ranging from 0.3 to 300 pM was included. After $24 \mathrm{~h}$ of exposure, the medium was discarded and cells were washed with low salt buffer and allowed to swell with $20 \mu \mathrm{l}$ of demineralized water. Cell plates were frozen at $-80^{\circ} \mathrm{C}$ for at least 30 min to allow lysis of the cells. Luciferase activity was measured as light production after addition of luciferin assay mix (Promega) on an Amelite luminometer (Amersham). Responses of the compounds were compared to the responses of the TCDD standard curve.

\subsection{Statistical analysis}

Statistical analysis was performed using SPSS 12.0 software for windows (SPSS, Chicago, IL). Continuous data were analyzed by one-way analysis of variance (ANOVA). Semi-quantitative data were tested for significance using the KruskalWallis $(\mathrm{K}-\mathrm{W})$ test for all groups; for post hoc testing $\mathrm{K}-\mathrm{W}$ was used for two independent samples. A difference between groups was considered statistically significant when $p<0.05$.

\section{Results}

\subsection{Chemical analysis of DE-71 and its internal dose}

Both fractions of DE-71 were analyzed to elucidate the composition of the DE-71 sample used in this study. Results are shown in Fig. 1 and Table 2 and Table 3. From analysis of the planar fraction, it appears that most PBDEs were separated from the PBDD/Fs, with the exception of the lower brominated BDE 28, which was 
retained longer in the $\mathrm{Al}_{2} \mathrm{O}_{3}$ column and eluted together with PBDD/Fs. Five contaminating PBDDs (compounds 1-6; Table 2), and two PBDFs (compounds 7 and 8 ; Table 2) were detected which could not be further identified; the retention times of one PBDF showed overlap with the 1,2,3,7,8-PeBDF standard.

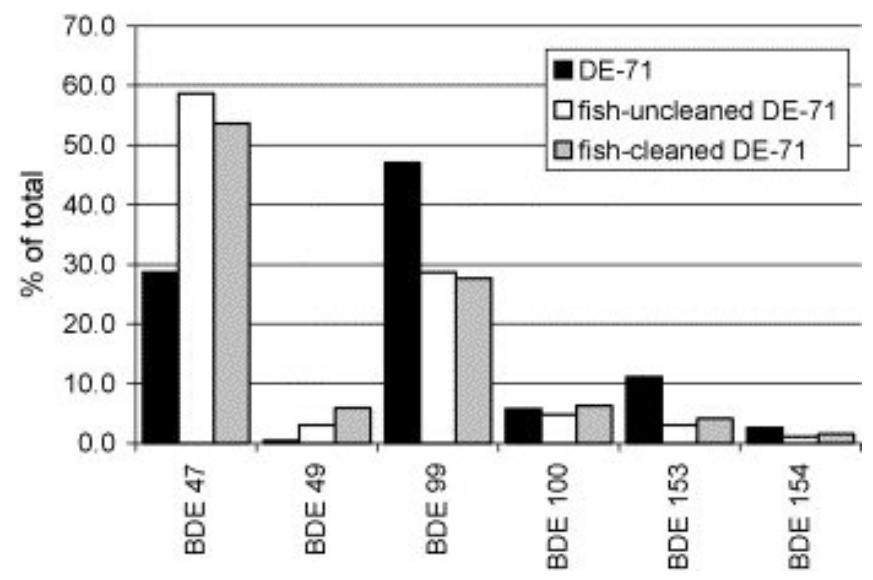

Fig. 1. Distribution of predominant BDE congeners in DE-71 and average distributions in zebrafish exposed to uncleaned and cleaned DE-71.

Table 2.

Indicative concentrations of PBDD/F congeners in DE-71 based on quantification with a 2,3,7,8-congener standard

\begin{tabular}{|l|l|}
\hline Planar compound & Estimated concentration (mg/kg DE71) \\
\hline (1) TetrabromoDD & 3 \\
\hline (2) PentabromoDD & 5 \\
\hline (3) PentabromoDD & 6 \\
\hline (4) HexabromoDD & 6 \\
\hline (5) HexabromoDD & 9 \\
\hline (6) HexabromoDD & 5 \\
\hline (7) PentabromoDF & 3 \\
\hline (8) PentabromoDF & 5 \\
\hline
\end{tabular}

a The retention time of this compound was very close to the retention time of $1,2,3,7,8$-pentabromoDF. 
Table 3.

Analysis of individual BDE congeners from pooled sample of four fish per exposure group in experiment $B$

\begin{tabular}{|c|c|c|c|c|c|c|c|}
\hline $\begin{array}{l}\text { Exposure (\% } \\
\text { in DE-71) }\end{array}$ & $\begin{array}{l}\text { Control } \\
(\mathrm{ng} / \mathrm{g})\end{array}$ & $\begin{array}{l}\text { Uncleaned } \\
0.1 \mathrm{mg} / \mathrm{I} \\
(\mathrm{ng} / \mathrm{g})\end{array}$ & $\begin{array}{l}\text { Uncleaned } \\
1 \mathrm{mg} / \mathrm{l} \\
(\mathrm{ng} / \mathrm{g})\end{array}$ & $\begin{array}{l}\text { Non- } \\
\text { planar } \\
0.1 \mathrm{mg} / \mathrm{l} \\
(\mathrm{ng} / \mathrm{g})\end{array}$ & $\begin{array}{l}\text { Non- } \\
\text { planar } \\
1 \mathrm{mg} / \mathrm{l} \\
(\mathrm{ng} / \mathrm{g})\end{array}$ & $\begin{array}{l}\text { Planar } \\
0.1 \mathrm{mg} / \mathrm{I} \\
(\mathrm{ng} / \mathrm{g})\end{array}$ & $\begin{array}{l}\text { Planar } \\
1 \mathrm{mg} / \mathrm{I} \\
(\mathrm{ng} / \mathrm{g})\end{array}$ \\
\hline BDE $28(0.1)$ & 3.4 & 1300 & 250 & 120 & 270 & 1600 & 19800 \\
\hline BDE 47 (28.7) & 36 & 297100 & 471100 & 270800 & 417400 & 160 & 670 \\
\hline BDE $49(0.4)$ & 1.5 & 2300 & 48100 & 34500 & 37400 & 3.0 & 12 \\
\hline BDE $66(0.4)$ & $<0.8$ & 830 & 4300 & 310 & 1900 & 120 & 1300 \\
\hline BDE $71(<0.03)$ & $<0.8$ & 62 & 470 & 92 & 410 & $<0.7$ & $<0.8$ \\
\hline BDE $75(<0.03)$ & 1.0 & 74 & 250 & 33 & 280 & $<0.7$ & $<0.8$ \\
\hline BDE $77(<0.03)$ & $<0.8$ & $<0.9$ & $<0.9$ & $<0.9$ & $<0.9$ & 9.0 & 55 \\
\hline BDE 85 (2.9) & $<0.7$ & 180 & 1600 & 290 & 5400 & $<0.6$ & $<0.7$ \\
\hline BDE 99 (47.0) & 5.6 & 138400 & 242400 & 124100 & 244400 & 39 & $<0.9$ \\
\hline BDE $100(5.7)$ & 2.3 & 16700 & 51000 & 15900 & 77800 & $<0.7$ & 27 \\
\hline BDE $119(<0.03)$ & $<0.8$ & 26 & 73 & 31 & 71 & $<0.7$ & $<0.8$ \\
\hline BDE $138(1.0)$ & $<0.8$ & 390 & 2200 & 390 & 4600 & $<0.7$ & $<0.8$ \\
\hline BDE 153 (11.1) & 2.1 & 11800 & 30900 & 11300 & 49800 & 10 & 25 \\
\hline BDE 154 (2.6) & 1.1 & 4400 & 10900 & 4200 & 17300 & 3.2 & 7.5 \\
\hline BDE $183(<0.03)$ & $<0.6$ & 34 & 170 & 48 & 350 & $<0.5$ & $<0.6$ \\
\hline BDE $190(<0.03)$ & 47 & $<0.9$ & $<0.9$ & $<0.9$ & 15 & $<0.7$ & $<0.8$ \\
\hline
\end{tabular}

Amounts are in $\mathrm{ng} / \mathrm{g}$ wet weight.

Pooled samples of four fish per group from experiment $B$ were analyzed for their PBDE content (Table 3). A weak background (predominantly BDE 47 and 190) was detected in the control group. Animals exposed to uncleaned DE-71 and cleaned DE-71 showed similar patterns of the predominant congeners BDE 47, 49, 99, 100, 153, and 154 (Fig. 1). BDE 28 levels in animals exposed to uncleaned DE-71 at $1 \mathrm{mg} / \mathrm{l}$ were low compared to the other groups. Animals exposed to only the planar fraction contained only very low amounts of PBDEs except for BDE 28, and less so for BDEs 47, 66, and 77.

\subsection{General toxicological parameters}

During experiment A, mortality was low (Table 1a). In the first week, one animal in the highest and one in the second highest concentration group died. In the highest concentration group, 3 out of 20 animals developed erratic swimming behavior during the fourth (and last) week of the experiment. Affected animals were swimming on their sides or upside-down and showed prolonged violent swimming when roused. Two of these animals died shortly after these symptoms 
developed; a third animal died later during the same week. Deceased animals were not included in the analysis of size and weight at the end of the total exposure period. Slight but statistically significant growth retardation (body weight and length) was found in the highest concentration group only (Table 1a). Animals in all groups were feeding normally, apart from the three that showed abnormal behavior, mentioned above. It should be noted that the highest concentration of DE-71 might have exceeded solubility in water containing $0.01 \%$ DMSO, judging from slight opacity of the water at the time of dosing. This opacity was of a transient nature and is not expected to have hindered the animals in feeding.

During experiment $B$, no mortality occurred. Transient water opacity was noted in the two groups of highest PBDE concentration (1 mg (un)cleaned DE-71/l, Table $1 b)$. Differences in growth were not observed between groups.

\subsection{Histopathology}

Whole body histological examination of 16 animals per group was performed in both experiments $A$ and $B$. Increased basophilia, indicative of highly active protein synthesis, of the liver was found in only two animals exposed to $0.010 \mathrm{mg}$ DE-71/I in experiment A. Vacuolization of hepatocytes was abundant in all groups including controls in both experiments. Marked vacuolization of the exocrine pancreas was present in two animals (exposed to 0.010 and $0.10 \mathrm{mg} \mathrm{DE}-71 / \mathrm{I}$ ) from experiment $A$. Thyroid epithelium retained its normal flat to cuboidal aspect in all groups and no apparent changes in follicular colloid were noticed. None of these changes were related to exposure.

Hermaphroditism (ovotestis) was found in two animals from the control group and 1 from each of the groups exposed to concentrations $0.010,0.032$, and $1.0 \mathrm{mg} / \mathrm{l}$ in experiment $\mathrm{A}$. The condition was characterized by the presence of differentiated oocytes in a gonad that showed clear signs of male differentiation (spermatogenesis). None of these testis-ova contained yolk granules. In both experiments $A$ and $B$, the undifferentiated nature of the gonad did not allow gender determination in some of the histologically examined animals. The prevalence of undifferentiated gonads or gender did not relate to concentration group in either experiment.

In the gills, lifting of epithelium with subepithelial proteinaceous material (branchial edema) was occasionally present in all dose groups, although less evident in the controls. Severe edema of the majority of secondary lamellae was significantly more frequent in animals from the groups of highest $D E-71$ concentration in experiment $\mathrm{A}(\mathrm{K}-\mathrm{W}: p<0.01)$. However, this finding was not reproduced in experiment $B$. Infiltration of the gill lamellae by lymphocytes was seen occasionally throughout all groups including controls in the present experiments. This condition was most pronounced at the bases of the primary lamellae, suggesting these lymphocytes are a functional part of the thymus, which particularly in juvenile zebrafish shows close anatomical association with the epithelial lining of the gill cavity. Since lymphocytes were rarely observed inside the epithelial layer, true inflammatory change (branchitis) is deemed absent in the present study.

A strong and clearly exposure-related statistically significant increase in immunoreactivity against CYP1A was observed in animals exposed to DE-71 in experiment A (Fig. 2 and Fig. 3). Increased CYP1A immunoreactivity was noted at the lowest DE-71 concentration $(0.01 \mathrm{mg} / \mathrm{l})$. This effect was most pronounced in endothelium of larger blood vessels throughout the body, particularly 
endocardium, ventral aorta, and branchial arteries. The well-vascularized gills were used for semi-quantitative analysis of CYP1A induction (Table 4a). In the higher concentration groups, besides the endothelium lining blood vessels, the pillar cells in the secondary gill lamellae were positive (Fig. 2a). In the control groups, immunoreactivity was absent (Fig. 2b). A distinct positive reaction was also found in the endothelium of abdominal blood vessels. In the liver, only weak CYP1A immunoreactivity was detected in parenchyma of exposed animals (Fig. 3). As in other organs, endothelium lining hepatic vascular tissue showed concentration dependent CYP1A immunoreactivity (Fig. 3). A less intense, but concentration related induction of immunoreactive CYP1A was furthermore present in bile duct epithelium (Fig. 3), throughout the intestinal tract mucosa, in the epithelium of predominantly proximal kidney tubules, skeletal muscle and Leydig cells of the skin (schreck-substanz cells). CYP1A immunohistochemistry in animals exposed to uncleaned DE-71 ( 0.1 and $1 \mathrm{mg} \mathrm{DE}-71 / \mathrm{I})$ and the planar fraction of $D E-71(1 \mathrm{mg} \mathrm{DE}-71 / \mathrm{I})$ in experiment $B$ confirmed the pattern described for experiment $A$. Exposure to cleaned $D E-71$ in experiment $B$ resulted in only occasional weak CYP1A immunoreactivity (Table 4b).

(a)
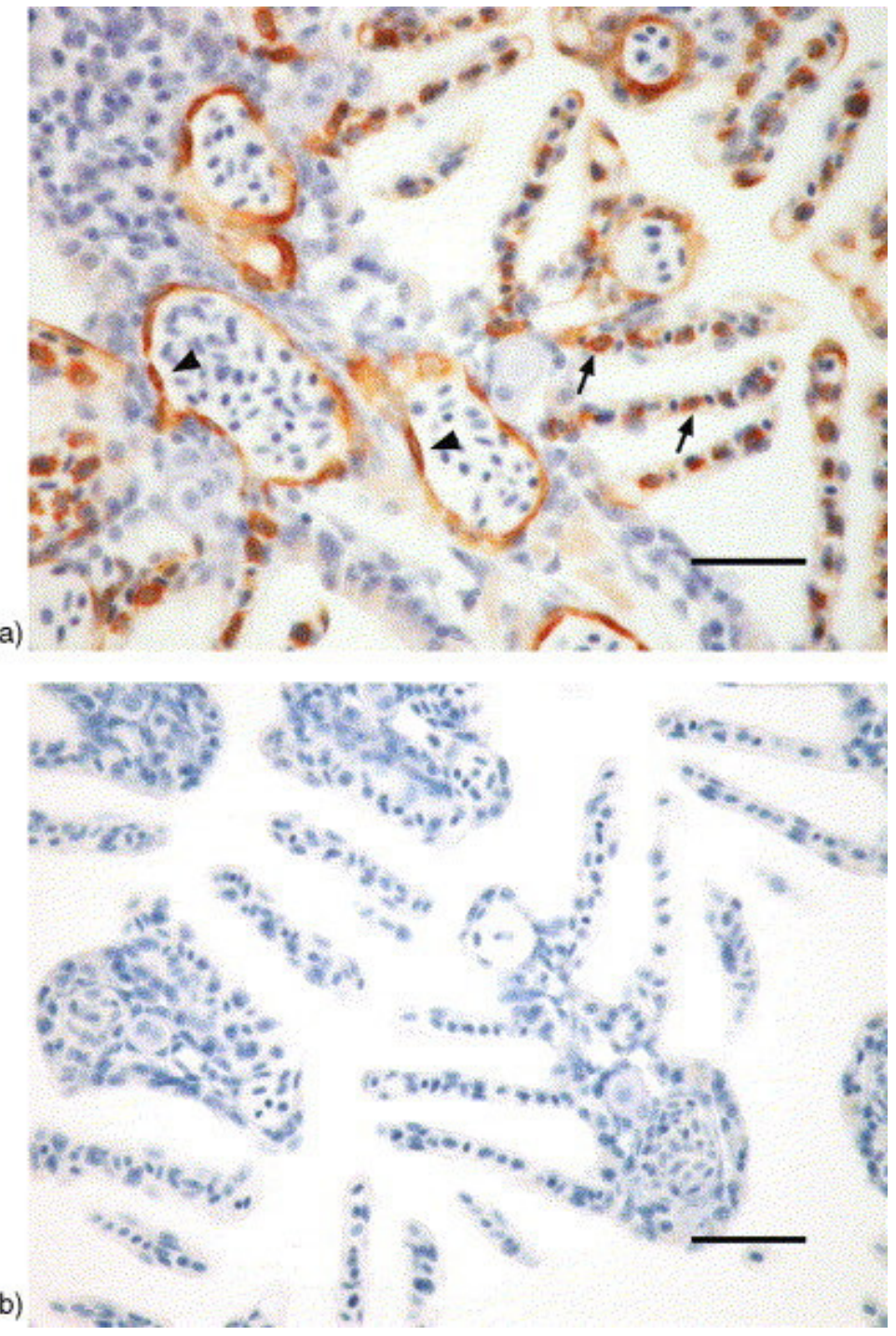

Fig. 2. (a) Gills from a zebrafish exposed to uncleaned DE-71 $(1 \mathrm{mg} / \mathrm{l})$. Immunoperoxidase staining using a primary antibody against CYP1A. Endothelium 
lining blood vessels (arrowheads) and pillar cells of secondary lamellae (arrows) show marked immunoreactivity. Hematoxylin counterstain, bar represents $25 \mu \mathrm{m}$.

(b) Gills from a control fish, stained according to the same procedure as in Fig. 1a. Bar represents $25 \mu \mathrm{m}$.

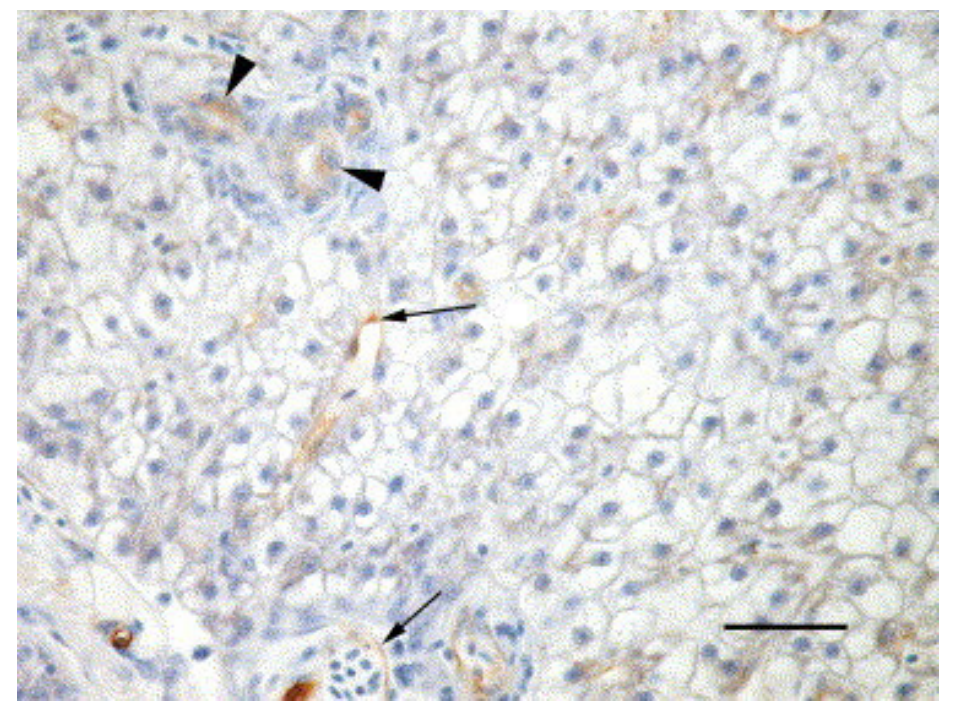

Fig. 3. Liver section from a zebrafish exposed to uncleaned DE-71 (1 mg/l). Indirect immunoperoxidase staining using anti-CYP1A as primary antibody. Diffuse grey-brown color of hepatocytes hints to some extent of immunoreactivity. Marked positivity in endothelium (arrow) and bile duct epithelium (arrowheads). Bar represents $25 \mu \mathrm{m}$.

Table 4a.

Experiment A: endothelial CYP1A immunoreactivity (gill endothelium)

\begin{tabular}{|l|l|l|l|l|}
\hline DE-71 dose (mg/l) & - & $\mathbf{\pm}$ & + & ++ \\
\hline 0.0 & 3 & & & \\
\hline $0.010^{* *}$ & & 3 & & \\
\hline $0.032^{* *}$ & & & 2 & 1 \\
\hline $0.10^{* *}$ & & & 1 & 2 \\
\hline $0.32^{* *}$ & & & 1 & 2 \\
\hline $1.0^{* *}$ & & & & 3 \\
\hline
\end{tabular}

Numbers represent sets of two animals; $(* *)$ groups differ significantly from control (K-W: $p<0.01)$; (-) no visible immunoreactivity; $( \pm)$ sporadic immunoreactivity; $(+)$ general immunoreactivity; $(++)$ strong general immunoreactivity. 
Table 4b.

Experiment B: endothelial CYP1A immunoreactivity (gill endothelium)

\begin{tabular}{|c|c|c|c|c|}
\hline Exposure & - & \pm & + & ++ \\
\hline Control (DMSO only) & 8 & & & \\
\hline Uncleaned DE-71: $0.1 \mathrm{mg} / \mathrm{I}^{* *}$ & & & 6 & 2 \\
\hline Uncleaned DE-71: $1 \mathrm{mg} / \mathrm{I}^{* *}$ & & & 2 & 6 \\
\hline Non-planar fraction from $0.1 \mathrm{mg} \mathrm{DE}-71 / \mathrm{I}\left(\right.$ cleaned DE-71) ${ }^{* *}, \# \#$ & 1 & 7 & & \\
\hline Non-planar fraction from $1 \mathrm{mg} \mathrm{DE}-71 / \mathrm{I}$ (cleaned DE-71) ${ }^{* *}, \# \#$ & 2 & 6 & & \\
\hline Planar fraction from $0.1 \mathrm{mg} \mathrm{DE-71/I}$ & 7 & & 1 & \\
\hline Planar fraction from $1 \mathrm{mg} \mathrm{DE}-71 / \mathrm{I}^{* *}$ & & & 4 & 4 \\
\hline
\end{tabular}

Numbers represent sets of two animals; $(* *)$ groups differ significantly from controls; $\left({ }^{\#}\right)$ groups differ significantly from uncleaned DE-71 at 0.1 and $1 \mathrm{mg} / \mathrm{l}$ $(\mathrm{K}-\mathrm{W}: p<0.01)$. ( $)$ no visible immunoreactivity; $( \pm)$ sporadic immunoreactivity; $(+)$ general immunoreactivity; $(++)$ strong general immunoreactivity.

Immunohistochemical staining for proliferating cell nuclear antigen (PCNA, experiment A) revealed no concentration-related alterations of cell proliferation in any of the organs examined. No indication was found for altered mitotic activity in the male gonads of exposed animals.

\subsection{Determination of TEQs using the DR-CALUX assay}

The TCDD toxic equivalency of uncleaned DE-71 was $2.0 \mathrm{ng}$ TEQ/g DE-71, whereas the planar contaminants isolated from the same amount of DE-71 yielded a 10 times higher TEQ (19.7 ng/g; Table 5). Luciferase induction by cleaned non-planar DE-71 was below the limit of detection. There were no indications for cytotoxicity at the concentrations tested.

Table 5.

Toxic equivalencies (TEQs) of the DE-71 stock solutions used in experiment $B$ determined by the DR-CALUX assay (limit of detection: $0.8 \mathrm{ng} / \mathrm{g}$ )

\begin{tabular}{|l|l|}
\hline Stock in DMSO & ng TEQ/g DE-71 \\
\hline Untreated (uncleaned) DE-71 & 2.0 \\
\hline Cleaned DE-71 & $<0.8$ \\
\hline Planar fraction of DE-71/ml & 19.7 \\
\hline
\end{tabular}




\section{Discussion}

BDEs 47 and 99 were the major components of the commercial Penta BDE mix, DE-71, which is in agreement with literature (Birnbaum and Staskal, 2004). The relative enrichment of BDE 47 in animals exposed to uncleaned DE-71 (Fig. 1) has been noted before and may have resulted from preferential uptake (de Wit, 2002); this could also explain the relative increase of BDE 49 in exposed zebrafish. The total amount of contaminating PBDD/Fs in the uncleaned DE-71 sample was estimated at $42 \mu \mathrm{g} / \mathrm{g}$ (Table 2 ) and was responsible for all of the dioxin-like toxic potency detected in vitro. A peak representing $3 \mu \mathrm{g}$ pentabrominated $\mathrm{DF} / \mathrm{g}$ of $\mathrm{DE}-71$ was detected eluting very close to $1,2,3,7,8$ PeBDF. This could be consistent with the report of $1,2,3,7,8-$ PeBDF as predominantly detected dioxin-like contaminant in DE-71 (Sanders et al., 2005), although the level was lower in that study $(19.8 \mathrm{ng} / \mathrm{g})$. With a relative potency in

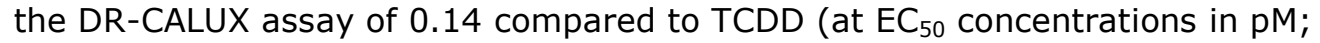
Behnisch et al., 2003), the present level of $1,2,3,7,8$-PeBDF could explain up to $225 \mathrm{ng}$ TEQ/g DE-71.

The present lack of consistent negative effects of PBDEs on growth is in agreement with earlier results in rainbow trout after oral exposure to approximately $20 \mathrm{mg}$ tetra- or penta-PBDE per $\mathrm{kg}$ for 22 days (Tjärnlund et al., 1998). Although in the present study, juvenile (growing) fish were used, and high internal PBDE concentrations were reached, mildly reduced length and weight ( $84 \%$ and $63 \%$ of the controls, respectively) were only observed in animals exposed to $1 \mathrm{mg} \mathrm{DE}-71 / \mathrm{I}$ in experiment $A$, indicating relatively limited toxic potential of lower brominated PBDEs in 4-8-weeks-old zebrafish. Lack of toxic effects of planar contaminants in the present study may be consistent with the predominance of TCDD-induced developmental toxicity in even younger, embryonal stages of zebrafish (Carney et al., 2006), and the relative insensitivity of zebrafish early life stages to TCDD when compared to other fish species (Elonen et al., 1998). Absence of general toxicological signs during experiment B remains unexplained and a clinical lowest observed effect concentration (LOEC) was not established.

The frequent hepatocellular vacuolization observed in all groups including controls in the present study may have obscured a dose related hepatocellular lipidosis, as was reported in adult three-spined stickleback after 3.5 months of oral exposure to another commercial penta-BDE mixture, Bromkal 70-5DE (total dose: 6.29 and $10.39 \mathrm{mg} / 20 \mathrm{fish}$; Holm et al., 1993). Oral exposure in that study may also have resulted in a more direct route to the liver, and the time between exposure and examination of the fish was longer. However, since no mention of a cleanup procedure was made in that study, the lipidosis could have resulted from exposure to planar contaminants as was observed in rainbow trout exposed to TCDD (Walter et al., 2000 and van der Weiden et al., 1992). Again, zebrafish may be less sensitive to dioxin-like chemicals than sticklebacks, or the contaminant levels in DE-71 may have been lower than in Bromkal 70-5DE.

The absence of morphologic thyroid changes indicates that exposure to commercial PeBDE did not affect thyroid function to a major extent in developing zebrafish. Although thyroxin (T4) levels were decreased in juvenile lake trout (Salvelinus namaycush) after single oral exposure to a mix of 13 BDE congeners including deca-BDE (BDE 209), triiodothyronin (T3) levels were unaffected (Tomy et al., 2004). Since T3 is the more active form of thyroid hormone (Brown et al., 2004), morphologic changes in the thyroid indicative of functional disorder tentatively relate to altered levels of T3 and TSH, rather than T4. In pubertal rats however, exposure to DE-71 decreased plasma levels of both thyroid hormones 
(T3 and T4), and increased plasma thyroid stimulating hormone (TSH) levels, resulting in thyroid morphology changes consistent with goiter after 3-4 weeks of exposure to a daily oral dose of $60 \mathrm{mg} / \mathrm{kg}$ (Stoker et al., 2004). Although zebrafish is capable of developing goiter when exposed to the anti-thyroid drug propylthiouracil (van der Ven et al., 2006), the lack of histological changes in the thyroid gland may be consistent with a relatively low sensitivity of fish to goitrogenic environmental contaminants (Leatherland, 1993).

In spite of (anti)-estrogenic properties of PBDEs in vitro (Meerts et al., 2001 and Nakari and Pessala, 2005), in vivo exposure to DE-71 did not produce morphologic evidence for endocrine disruption on the reproductive level in the present study. Mitotic activity in male gonads, evaluated by PCNA immunostaining, was similar in all groups. Liver H\&E staining, a sensitive indicator for production of vitellogenin in zebrafish exposed to known estrogens (van der Ven et al., 2003), was not concentration-dependently affected. Lack of effects in our experiments may reflect the rather low relative (anti-)estrogenic potencies of PBDEs, and the low uptake of weak ER agonist BDEs compared to inactive ones (e.g. BDE 47; Meerts et al., 2001).

The concentration-dependent induction of immunodetectable CYP1A in endothelium in the gills, heart and abdominal organs, hepatocytes, bile duct epithelium, and epithelium of the gastro-intestinal tract and kidney of animals exposed to uncleaned DE-71 resembles CYP1A induction patterns found in TCDDexposed fish remarkably well (Buchmann et al., 1993 and Zodrow et al., 2004, D. rerio; Stegeman et al., 1991, S. chrysops; Grinwis et al., 2000 and Grinwis et al., 2001, Platichthys flesus). The markedly reduced CYP1A induction in animals exposed to cleaned DE-71 indicates that the planar contaminants in DE-71 were largely responsible. Although analysis of fish indicated a relatively large amount of BDE 28 in the planar fraction, BDE 28 was not a potent AhR agonist in primary cultured rat hepatocytes (Chen and Bunce, 2003), and recently presented as an AhR antagonist (Hamers et al., 2006). Presently, CYP1A induction after exposure to water-borne DE-71 or the planar fraction of DE-71 was most conspicuous in gill endothelium, whereas previously, in adult zebrafish exposed to TCDD via intraperitoneal injection, immunodetection of CYP1A was more intense in internal organs (kidney, liver, gastrointestinal tract; Zodrow et al., 2004). Water-borne exposure may have resulted in a relatively higher exposure of the gills in the present study. In addition, the gills are highly vascularized, and in lake trout early life stages, endothelium was shown to be sensitive to induction of CYP1A by TCDD (Guiney et al., 1997). In that study, vascular immunodetection of CYP1A coincided with pericardial, yolk sac and meningeal edema, indicating a relation with vascular functional disorder. In zebrafish, pericardial and cranial edema was reported in newly hatched larvae exposed to TCDD (Wannemacher et al., 1992) and in larvae exposed during the first 10 days after fertilization (Henry et al., 1997), suggesting a similar target for AhR-mediated toxicity in this species. Since hypoxia was shown to reduce AhR-mediated effects and edema in zebrafish early life stages exposed to TCDD (Prasch et al., 2004), locally higher oxygen levels may result in a relatively high sensitivity of the gills compared to internal organs in post-hatch fish. Although concentration dependent branchial edema was only found in experiment $A$, it is tempting to assume a relation with AhR-mediated toxicity.

The importance of planar contaminants for in vivo induction of CYP1A by uncleaned DE-71 was confirmed in vitro by the lack of an AhR-mediated DRCALUX response to cleaned DE-71, in spite of the presence of some AhR agonist PBDE congeners (namely BDEs 66, 85, 100 and 153; Chen and Bunce, 2003). The planar fraction isolated from the DE-71 stock however induced a 10 times 
stronger AhR-agonist response compared to the original uncleaned stock. The relatively low induction by uncleaned $D E-71$ possibly resulted from inhibition of AhR-mediated gene expression by some of the PBDEs present (Chen and Bunce, 2003, Kuiper et al., 2004 and Peters et al., 2004). In spite of the lower DR-CALUX response, zebrafish exposed to uncleaned DE-71 showed an equally strong immunostaining of CYP1A protein as fish exposed to the planar components alone. This is consistent with the failure of DE-71 to reduce $\beta$-naphtoflavoneinduced EROD activity in ovo in killifish ( $F$. heteroclitus) within 1 day of exposure (Timme-Laragy et al., 2006). The apparent lack of attenuation of AhR mediated CYP1A induction in both the present and the killifish studies is possibly caused by preferential uptake of planar components; in the present study, the longer exposure period of the fish when compared to the H4IIE-luc cells could have enhanced this effect, resulting in stronger AhR activation in vivo. Because of the low absolute concentrations of PBDD/Fs and the small volume of the samples, PBDD/Fs were expected to be below the limits of detection and therefore not analyzed in the fish in the present study, and a ratio between planar and nonplanar components was not established.

\section{Conclusions}

Commercial pentabromodiphenylether induces CYP1A in various tissues in juvenile zebrafish ( $D$. rerio) in a similar pattern as observed after exposure to dioxin-like compounds, with endothelium as the predominantly reacting cell-type. Although weak AhR activation has been reported for several PBDE congeners, in the present study cleaned DE-71 did not induce a significant DR-CALUX response, and only limited CYP1A immunoreactivity was observed in juvenile zebrafish. Based on the DR-CALUX response to the planar fraction alone, planar contaminants accounted for $19.7 \mathrm{ng} T E Q / g ~ D E-71$. The present findings confirm $1,2,3,7,8$-PeBDF as an important dioxin-like contaminant in DE-71. Although the levels of planar contaminants in commercial pentabromodiphenylether mixtures may vary, they are the likely cause for AhR mediated effects in this and probably other studies with uncleaned PBDE mixtures. This should be taken into account when interpreting TCDD equivalencies reported for commercial PBDE mixtures. Immunohistochemical analysis of CYP1A proved a sensitive method for detection of AhR agonists in fish exposed to complex mixtures where the overall composition may modulate dioxin-like activity.

\section{Acknowledgements}

Hundreds of excellent tissue sections were cut and stained by Wil Steenbergen, Helena Priem and Ronald Molenbeek at our histotechnical lab. John Rowaan is responsible for the fish breeding at IRAS. Hans van den Berg is acknowledged for performing the DR-CALUX assay. The present research was carried out within the EU-supported project "Toxicology of Brominated Flame Retardants as Suspected Endocrine Disrupters for Human and Wildlife Health" (acronym: FIRE; EU contract no. QLK4-CRT-2002-00596). 


\section{References}

Anderson and Blomkvist, 1981 Ö. Anderson and G. Blomkvist, Polybrominated aromatic pollutants found in fish in Sweden, Chemosphere 10 (1981), pp. 1051-1060.

Birnbaum and Staskal, 2004 L.S. Birnbaum and D.F. Staskal, Brominated flame retardants: cause for concern?, Environ. Health Perspect. 112 (2004), pp. 9-17.

Birnbaum et al., 2003 L.S. Birnbaum, D.F. Staskal and J.J. Diliberto, Health effects of polybrominated dibenzo-p-dioxins (PBDDs) and dibenzofurans (PBDFs), Environ. Intern. 29 (2003), pp. 855-860.

Behnisch et al., 2003 P.A. Behnisch, K. Hosoe and S.-I. Sakai, Brominated dioxin-like compounds: in vitro assessment in comparison to classical dioxin-like compounds and other polyaromatic compounds, Environ. Intern. 29 (2003), pp. 861-877.

Boer, de 1989 J. de Boer, Organochlorine compound and bromodiphenyl ethers in livers of Atlantic cod (Gadus morhua) from the North Sea 1977-1987, Chemosphere 18 (1989) (11/12), pp. 2131-2140.

Boer, de et al., 1998 J. de Boer, P.G. Wester, H.J.C. Klamer, W.E. Lewis and J.P. Boon, Do flame retardants threaten ocean life?, Nature 394 (1998), pp. 28-29.

Brown et al., 2004 S.B. Brown, B.A. Adams, D.G. Cyr and J.G. Eales, Contaminant effects on the teleost fish thyroid, Environ. Toxicol. Chem. 23 (2004), pp. 1680-1701.

Buchmann et al., 1993 A. Buchmann, R. Wannemacher, E. Kulzer, D.R. Buhler and K.W. Bock, Immunohistochemical ocalization of the P450 isoenzymes LMC2 and LM4B (P401A1) in 2,3,7,8tetrachlorodibenzo-p-dioxin-treated zebrafish (Brachydanio rerio), Toxicol. Appl. Pharmacol. 123 (1993), pp. 160-169.

Burreau et al., 2004 S. Burreau, Y. Zebühr, D. Broman and R. Ishaq, Biomagnification of polychlorinated biphenyls (PCBs) and polybrominated diphenyl ethers (PBDEs) studied ip pike (Esox lucius), perch (Perca fluviatilis) and roach (Rutilus rutilus) from the Baltic Sea, Chemosphere $\mathbf{5 5}$ (2004), pp. 1043-1052.

Carney et al., 2006 S.A. Carney, A.L. Prasch, W. Heideman and R.E. Peterson, Understanding dioxin developmental toxicity using the zebrafish model, Birth Defects Res. A. 76 (2006), pp. 7-18.

Chen and Bunce, $2003 \mathrm{G}$. Chen and N. Bunce, Polybrominated diphenylethers as Ah receptor agonists and antagonists, Toxicol. Sci. 76 (2003), pp. 310-320.

Elonen et al., 1998 G.E. Elonen, R.L. Spehar, G.W. Holcombe, R.D. Johnson, J.D. Fernandez, R.J. Erickson, J.E. Tietge and P.M. Cook, Comparative toxicity of 2,3,7,8-tetrachlorodibenzo- $p$-dioxin to seven freshwater fish species during early life-stage development, Environ. Toxicol. Chem. 17 (1998), pp. 472-483.

Grinwis et al., 2000 G.C.M. Grinwis, H.T. Besselink, E.J. van den Brandhof, A.S. Bulder, M.Y. Engelsma, R.V. Kuiper, P.W. Wester, M.A. Vaal, A.D. Vethaak and J.G. Vos, Toxicity of TCDD in European flounder (Platichthys flesus) with emphasis on histopathology and cytochrome P450 1A induction in several organ systems, Aquat. Toxicol. 50 (2000), pp. 387-401.

Grinwis et al., 2001 G.C.M. Grinwis, E.J. van den Brandhof, M.Y. Engelsma, R.V. Kuiper, M.A. Vaal, A.D. Vethaak, P.W. Wester and J.G. Vos, Toxicity of PCB-126 in European flounder (Platichthys flesus) with emphasis on histopathology and cytochrome P450 1A induction in several organ systems, Arch. Toxicol. 75 (2001), pp. 80-87.

Guiney et al., 1997 P.D. Guiney, R.M. Smolowitz, R.E. Peterson and J.J. Stegeman, Correlation of 2,3,7,8-tetrachlorodibenzo-p-dioxin induction of cytochrome P4501A in vascular endothelium with toxicity in early life stages of lake trout, Toxicol. Appl. Pharmacol. 142 (1997), pp. 256-273.

Hamers et al., 2006 T. Hamers, J.H. Kamstra, E. Sonneveld, A.J. Murk, M.H.A. Kester, P.L. Andersson, J. Legler and A. Brouwer, In vitro profiling of the endocrine disrupting potency of brominated flame retardants, Toxicol. Sci. 92 (2006), pp. 157-173. 
Henry et al., 1997 T.R. Henry, J.M. Spitsbergen, M.W. Hornung, C.C. Abnet and R.E. Peterson, Early life stage toxicity of 2,3,7,8-tetrachlorodibenzo- $p$-dioxin in zebrafish (Danio rerio), Toxicol. Appl. Pharmacol. 142 (1997), pp. 56-68.

Holm et al., 1993 G. Holm, L. Norrgren, T. Andersson and A. Thurén, Effects of exposure to food contaminated with PBDE, PCN or PCB on reproduction, liver morphology and cytohrome P450 activity in the three-spined stickleback, Gasterosteus aculeatus, Aquat. Toxicol. 27 (1993), pp. 33-50.

Hornung et al., 1996 W.M. Hornung, E.W. Zabel and R.E. Peterson, Toxic equivalency factors of polybrominated dibenzo- $p$-dioxin, dibenzofuran, biphenyl, and polyhalogenated diphenyl ether congeners based on rainbow trout early life stage mortality, Toxicol. Appl. Pharmacol. 140 (1996), pp. 227-234.

Hsiao and Tsai, 2003 C.-D. Hsiao and H.-J. Tsai, Transgenic zebrafish with fluorescent germ cell: a useful tool to visualize germ cell proliferation and juvenile hermaphroditism in vivo, Dev. Biol. 262 (2003), pp. 313-323.

Ikonomou et al., 2002 M.G. Ikonomou, S. Rayne and R.F. Addison, Exponential increases of the brominated flame retardants, polybrominated diphenyl ethers, in the Canadian Arctic from 1981 to 2000, Environ. Sci. Technol. 36 (2000), pp. 1886-1892.

Jansson et al., 1993 B. Jansson, R. Andersson, L. Asplund, K. Litzén, K. Nylund, U. Sellström, U. Uvemo, C. Wahlberg, U. Wildeqvist, T. Odsjö and M. Olsson, Chlorinated and brominated persistent organic compounds in biological samples from the environment, Environ. Toxicol. Chem. 12 (1993), pp. $1163-1174$.

Kierkegaard et al., 1999 A. Kierkegaard, L. Balk, U. Tjärnlund, C.A. de Wit and B. Jansson, Dietary uptake and biologiocal effects of decabromodiphenyl ether in rainbow trout (Oncorrhynchus mykiss), Environ. Sci. Technol. 33 (1999), pp. 1612-1617.

Kierkegaard et al., 2004 A. Kierkegaard, A. Bignert, U. Sellstrom, M. Olsson, L. Asplund, B Jansson and C.A. de Wit, Polybrominated diphenyl ethers (PBDEs) and their methoxylated derivatives in pike from Swedish waters with emphasis on temporal trends, 1967-2000, Environ. Pollut. 130 (2004), pp. 187-198.

Korytar et al., 2005 P. Korytar, J. Parera, P.E.G. Leonards, F.J. Santos, J. de Boer and U.A.Th. Brinkman, Characterization of polychlorinated n-alkanes using comprehensive two-dimensional gas chromatography-electron-capture negative ionization time-of-flight mass spectrometry, $\mathrm{J}$. Chromatogr. A 1086 (2005), pp. 71-82.

Kuiper et al., 2004 R.V. Kuiper, A. Bergman, J.G. Vos and M. van den Berg, Some polybrominated diphenyl ether (PBDE) flame retardants with wide environmental distribution inhibit TCDD-induced EROD activity in primary cultured carp (Cyprinus carpio) hepatocytes, Aquat. Toxicol. 68 (2004), pp. 129-139.

Leatherland, 1993 J.F. Leatherland, Field observations on reproductive and developmental dysfunction in introduced and native salmonids from the Great Lakes, J. Great Lakes Res. 19 (1993), pp. 737751.

Meerts et al., 2001 I.A.T.M. Meerts, R.J. Letcher, S. Hoving, G. Marsh, $\AA$. Bergman, J.G. Lemmen, B. van der Burg and A. Brouwer, In vitro estrogenicity of polybrominated diphenyl ethers, hydroxylated PBDEs, and polybrominated bisphenol A compounds, Environ. Health Perspect. 109 (2001), pp. 399407.

Murk et al., 1996 A.J. Murk, J. Legler, M.S. Denison, J.P. Giesy, C. van de Guchte and A. Brouwer, Chemical-activated luciferase gene expression (CALUX): a novel in vitro bioassay for Ah receptor active compounds in sediments and pore water, Fundam. Appl. Toxicol. 33 (1996), pp. 149-160.

Murk et al., 1998 A.J. Murk, P.E.G. Leonards, B. van Hattum, R. Luit, M.E.J. van der Weiden and M. Smit, Application of biomarkers for exposure and effect of polyhalogenated aromatic hydrocarbons in naturally exposed European otters (Lutra lutra), Environ. Tox. Pharm. 6 (1998), pp. 91-102.

Nakari and Pessala, 2005 T. Nakari and P. Pessala, In vitro estrogenicity of polybrominated flame retardants, Aquat. Toxicol. 74 (2005), pp. 272-279. 
Norrgren et al., 1993 L. Norrgren, T. Andersson and M. Björk, Liver morphology and cytochrome-P450 activity in fry of rainbow-trout after microinjection of lipid-soluble xenobiotics in the yolk-sac embryos, Aquat. Toxicol. 26 (1993), pp. 307-316.

Peters et al., 2004 A.K. Peters, K. van Londen, $\AA$. Bergman, J. Bohonowych, M.S. Denison, M. van den Berg and J.T. Sanderson, Effects of polybrominated diphenyl ethers on basal and TCDD-induced ethoxyresorufin activity and cytochrome P450-1A1 expression in MCF-7, HepG2, and H4IIE cells, Toxicol. Sci. 82 (2004), pp. 406-488.

Prasch et al., 2004 A.L. Prasch, E.A. Andreasen, R.E. Peterson and W. Heideman, Interactions between 2,3,7,8-tetrachlorodibenzo- $p$-dioxin (TCDD) and hypoxia signaling pathways in zebrafish: hypoxia decreases responses to TCDD in zebrafish embryos, Toxicol. Sci. 78 (2004), pp. 68-77.

Ramos et al., 1997 L. Ramos, L.M. Hernandez and M.J. Gonzalez, Elution pattern of planar chlorinated biphenyls polychlorinated dibenzo- $p$-dioxins/dibenzofurans chromatographic adsorbents and factors affecting the retention. Possibilities of selective separation of both families, J. Chromatogr. A 759 (1997), pp. 127-137.

Sakai et al., 2001 S.-I. Sakai, J. Watanabe, Y. Honda, H. Takatsuki, I. Aoki, M. Futamatsu and K. Shiozaki, Combustion of brominated flame retardants and behavior of its byproducts, Chemosphere 42 (2001), pp. 519-531.

Sanders et al., 2005 J.M. Sanders, L.T. Burka, C.S. Smith, W. Black, R. James and M.L. Cunningham, Differential expression of CYP1A, 2B, and 3A genes in the F344 rat following exposure to a polybrominated diphenyl ether mixture or individual components, Toxicol. Sci. 88 (2005), pp. 127133.

Schriks et al., 2006 M. Schriks, C.M. Vrabie, A.C. Gutleb, E.J. Faassen, I.M.C.M. Rietjens and A.J. Murk, T-screen to quantify functional potentiating, antagonistic and thyroid hormone like activities of polyhalogenated aromatic hydrocarbons (PHAHs), Toxicol. In Vitro 20 (2006), pp. 490-498.

Sellström et al., 1993 U. Sellström, B. Jansson, A. Kierkegaard and C. de Wit, Polybrominated diphenyl ethers (PBDE) in biological samples from the Swedish environment, Chemosphere 26 (1993), pp. 1703-1718.

Sellström et al., 1998 U. Sellström, K. Kierkegaard, C. de Wit and B. Jansson, Polybrominated diphenyl ethers and hexabromocyclododecane in sediment and fish from a Swedish river, Environ. Toxicol. Chem. 17 (1998), pp. 1065-1072.

Sellström et al., 2003 U. Sellström, A. Bignert, A. Kierkegaard, L. Haggberg, C.A. de Wit, M. Olsson and $B$. Jansson, Temporal trend studies on tetra-and pentabrominated diphenyl ethers and hexabromocyclododecane in guillemot egg from the Baltic Sea, Environ. Sci. Technol. 37 (2003), pp. 5496-5501.

Söderström et al., 2004 G. Söderström, U. Sellström, C.A. de Wit and M. Tysklind, Photolytic debromination of decabromodiphenyl ether (BDE 209), Environ. Sci. Technol. 38 (2004), pp. 127132.

Stegeman et al., 1991 J.J. Stegeman, R.M. Smolowitz and M.E. Hahn, Immunohistochemical localization of environmentally induced cytochrome P4501A1 in multiple organs of the marine teleost Stenotomus chrysops (Scup), Toxicol. Appl. Pharmacol. 110 (1991), pp. 486-504.

Stoker et al., 2004 T.E. Stoker, S.C. Laws, K.M. Crofton, J.M. Hedge, J.M. Ferell and R.L. Cooper, Assessment of DE-71, a commercial polybrominated diphenyl ether (PBDE) mixture, in the EDSP male and female pubertal protocols, Toxicol. Sci. 78 (2004), pp. 144-155.

Timme-Laragy et al., 2006 A.R. Timme-Laragy, E.D. Levin and R.T. Di Giulio, Developmental and behavioral effects of embryonic exposure to the polybrominanted diphenylether mixture DE-71 in the killifish (Fundulus heteroclitus), Chemosphere 62 (2006), pp. 1097-1140.

Tjärnlund et al., 1998 U. Tjärnlund, G. Ericson, U. Örn, C. de Wit and L. Balk, Effects of two polybrominated diphenyl ethers on rainbow trout (Oncorhynchus mykiss) exposed via food, Mar. Environ. Res. 46 (1998), pp. 107-112. 
Tomy et al., 2004 G.T. Tomy, V.P. Palace, T. Halldorson, E. Braekevelt, R. Danell, K. Wautier, B. Evans, L. Brinkworth and A.T. Fisk, Bioaccumulation, biotransformation, and biochemical effects of brominated diphenyl ethers in juvenile lake trout (Salvelinus namaycush), Environ. Sci. Technol. 38 (2004), pp. 1496-1504.

Ven, van der et al., 2003 L.T.M. van der Ven, P.W. Wester and J.G. Vos, Histopathology as a tool for the evaluation of endocrine disruption in zebrafish (Danio rerio), Environ. Toxicol. Chem. 22 (2003), pp. 908-913.

Ven, van der et al., 2006 L.T.M. van der Ven, E.-J. van den Brandhof, J.H. Vos, D.M. Power and P.W. Wester, Effects of the antithyroid agent propylthiouracil in a partial life cycle assay with zebrafish, Environ. Sci. Technol. 40 (2006), pp. 74-81.

Vives et al., 2004 I. Vives, J.O. Grimalt, S. Lacorte, M. Guillamon, D. Barcelo and B.O. Rosseland, Polybromodiphenyl ether flame retardants in fish from lakes in European high mountains and Greenland, Environ. Sci. Technol. 38 (2004), pp. 2338-2344.

Walter et al., 2000 G.L. Walter, P.D. Jones and J.P. Giesy, Pathologic alterations in adult rainbow trout, Onchorhynchus mykiss, exposed to dietary 2,3,7,8-tetrachlorodibenzo-p-dioxin, Aquat. Toxicol. 50 (2000), pp. 287-299.

Wannemacher et al., 1992 R. Wannemacher, A. Rebstock, E. Kulzer, D. Schrenk and K.W. Bock, Effects of 2,3,7,8-tetraclorodibenzo- $p$-dioxin on reproduction and oogenesis in zebrafish (Brachydanio rerio), Chemosphere 24 (1992), pp. 1361-1368.

Watanabe et al., 1987 I. Watanabe, T. Kashimoto and R. Tatsukawa, Polybrominated biphenyl ethers in marine fish, shellfish and river and marine sediments in Japan, Chemosphere 16 (1987), pp. 23892396.

Weiden, van der et al., 1992 M.E.J. van der Weiden, J. van der Kolk, R. Bleumink, W. Seinen and M. van den Berg, Concurrence of cytochrome P450 1A1 induction and toxic effects after administration of a low dose of 2,3,7,8-dibenzo- $p$-dioxin (TCDD) in the rainbow trout (Oncorhynchus mykiss), Aquat. Toxicol. 24 (1992), pp. 123-142.

Wit, de 2002 C.A. de Wit, An overview of brominated flame retardants in the environment, Chemosphere 46 (2002), pp. 583-624.

Zhu and Hites, 2004 L.Y. Zhu and R.A. Hites, Temporal trends and spatial distributions of brominated flame retardants in archived fishes from the great lakes, Environ. Sci. Technol. 38 (2004), pp. 27792784 .

Zodrow et al., 2004 J.M. Zodrow, J.J. Stegeman and R.L. Tanguay, Histological analysis of acute toxicity of 2,3,7,8-tetrachlorodibenzo-p-dioxin (TCDD) in zebrafish, Aquat. Toxicol. 66 (2004), pp. 2538. 